\title{
Social Engagement and the Construction of Place
}

KATIE MACDONALD

Virginia Tech

Today's Citizen Architect ${ }^{1}$ must navigate a world rewired for networked experience. If the internet saw the advent and realization of place as a purely social construct, studying networked engagement and the social art practices that followed offers insights into how architects might galvanize participation and meaning back into the physical world.

Place attachment theory once emphasized the way that the physical informs meaning-"attributes of the environment are associated with characteristic experiences. Symbolic meanings are produced from these experiences, and these meanings in turn underpin place attachment and satisfaction." ${ }^{2}$ In this new world, symbolic meanings, via experience and engagement, might instead be formed with the intention of creating placevirtual or physical.

\section{SOCIAL NETWORKS}

The internet's early days hatched cheap and accessible sites where users could connect regardless of origin or physical location, fundamentally reframing how social networks are constructed and lived. Giving venue to the isolated with a twenty-four hour hangout and community, the web brought a constant influx of new potentials - for relationships, for connections, for distractions, for life. Decades later, the social houses of the internet have largely consolidated to a few saturated hangouts (Facebook, Twitter, Snapchat, Instagram, WeChat, Reddit), on the one hand bringing the demise of the physical haunts where communities once formed, but at the same time providing a new model for building communities and constructing lean-to-produce, potent, and multivalent places. The simultaneous economy and power of internet sites suggest a strategy for constructing place in areas of the built environment that are limited in means.

Artists such as Miranda July leverage communication frameworks to intervene in the space of the internet, distributing authorship and inviting the public to engage. Her projects include Learning to Love You More, a crowd-sourced ever-changing online exhibition, and Somebody, a mobile application that allows users to send messages from their phones but have the messages delivered in person by other users. Because art in this realm is fundamentally about gathering,

\begin{abstract}
The glory of the network artist derives fundamentally from the ephemerality of his or her work, the necessity to keep on making, to keep one step ahead, or more if possible. Working without product is only the first step in this process, working at the level of ideas. ${ }^{3}$
\end{abstract}

The engagement with the space of the internet extends the strategies developed by communication media artists during the second half of the twentieth century; mail art, radio art, satellite art, and Fluxus art harnessed distribution networks as a conceptual framework for creating art with multiple authors.

\section{SOCIALLY ENGAGED ART}

Recent developments in socially engaged art build on the frameworks of internet art, but resituate the techniques of such immaterial places to physical spaces IRL (in real life). For both network art and socially engaged art practice, the dominant vehicle is public discourse; artist and theorist Pablo Helguera defines the socially engaged artist as "an individual whose specialty includes working with society in a professional capacity." If AlA doctrine suggests that this is and has long been the case for architects, Helguera's definition can be expanded to specify that working with society demands an ethical and participatory commitment.

Like network art, socially engaged practice draws power from its ability to create art as a social construct regardless of budget or the existing built environment. The city of Detroit presents an opportunity for art to bridge stark class distinctions and racial tensions, creating a spirit of creativity and hope that is more shared sentiment than visible, physical reality. Claire Pentecost touches on the illusive creative renaissance celebrated by Detroit residents:

After decades of structural abandonment they seem to understand like few Americans do, that no one is going to do it for them. In Detroit, we were struck by a stubborn optimism that I have not actually encountered anywhere else in this country. [...] It is part of how people feel there is a future, a tomorrow which might look different, and it is certainly a requisite to the agency necessary to directing change. [...] Material conditions are utterly impoverished in the very places where people are doggedly creating new social and material support systems. One has to have a powerful imagination to see what they are talking about in these destitute spaces. ${ }^{5}$ 
The economy of socially engaged practice helps bolster such work far beyond derelict cities like Detroit. Underlying market factors and the resulting cultural landscape shape the contemporary production of public art:

Culture is the public space where common matters, shared solidarities, and public engagements provide the fundamental elements of democracy. Culture is also the pedagogical and political ground in which shared solidarities and a global public sphere can be imagined as a condition of democratic possibilities. [...] Culture as an emancipatory force affirms the social as a fundamentally political space, just as neo-liberalism attempts within the current historical moment to deny culture's relevance as a democratic sphere and its centrality as a political necessity. ${ }^{6}$

The linking of the social to the political promotes shared experience as a natural space for political discourse. This type of space is lacking in today's neo-liberal, privatized city-a landscape in which private clients have strategically neglected the creation of social spaces and undermined the authenticity of such spaces in order to prevent gathering and limit liability concerns. Such privatized "public" spaces also tend to be highly monitored, whether by the more obvious means of guards and cameras or more subtle tactics like bright lighting or speakers emitting high pitched sounds.

Martin Zebracki's study of Amsterdam and Ghent illuminates certain factors dictating the success or failure of public art networks. He finds that (1) more art, spatially dispersed art, and diverse art is produced under urban renewal strategies and in areas not dominated by tradition, (2) public art is made up of two dominant categories, "centralized flagship-art projects" (which result in good publicity but may not spur more projects) and "temporary interventions"|"socially engaged processes" (which tend to be more innovative, inspiring creative diversity), and (3) public art "requires a proper institutional infrastructure to channel both public and private public-art initiatives into a creative process that is favorably perceived in spatio-organizational and financial terms" because ultimately, funding and policy become important factors in the successful fruition of a given project.?

The framework of social practice requires external participation and thus begins to edge out of the disciplinary territory of art and into the realm of activism and sociology. The resulting intersection of disciplines provides artists with the advantage of bringing both artistic tools and activist values into action. This combination renders socially engaged art an interdisciplinary activity that draws power from its ability to connect and influence multiple spheres.

The requisite economy and accessibility of social practice privileges leaner art forms. Performance becomes a leading vehicle; expressive, deeply human, and multi-sensory, performing arts are easy to connect to and economical to produce. Using human experience and expression as the main tools of an artistic practice, the barriers to entry to artmaking are lowered: art is both inclusive to its audience and to artists themselves.

Socially engaged art teeters tenuously between service and art, often moving into the latter category via the inclusion of some aspect of performance. The title of activist seems to establish a middle ground, marrying the analysis and deliberation of the artist with the practical generosity of the serviceman. Nonetheless, contradictions remain between the two roles and bring back the question of what defines art and who artists serve. Helguera attempts to mitigate the confusion by shedding light on the key differences:

Social work is a value based profession based on a tradition of beliefs and systems that aim for the betterment of humanity [...] An artist, in contrast, may subscribe to the same values but make work that ironizes, problematizes, and even enhances tensions around those subjects, in order to provoke reflection. ${ }^{8}$

Helguera's definition suggests a process for socially engaged art making: the artist approaches a found condition critically, exposes and frames problems within the condition, and ultimately presents this re-framing to an audience, in turn inviting viewers to contemplate the condition. Therefore, the most telling difference between social work and socially engaged art is art's inclusion of an audience. Service is performed to solve a problem and then is complete. Art is performed to illuminate a condition for an audience.

Still, in Helguera's definition of socially engaged art, the characterization of disciplines is perhaps one-sided. While the term art is singularly defined, socially engaged takes on a broader range, including activist, community oriented, pedagogical, political, sociological, organizational, or other. ${ }^{9}$ Equal parts art and engagement, socially engaged art would increase its capabilities and impact by widening its definition of art. With intrinsic biases toward practical application, organization, and human interaction, design fields such as architecture, furniture, landscape, and planning fit the bill for an art that involves the public through design and action. Working off of this expanded definition, buildings can become pedagogical tools for change; landscapes can become interactive spaces in which social relationships transform; cities can become canvasses for political discussion.

In this new social practice, art and design meet at an intersection of poetry and utility. If "The expertise of the artist lies [...] in being a non-expert, a provider of frameworks on which experiences can form and sometimes be directed and channeled to generate new insights around a particular issue,"10 
the artist classification closely aligns with the traditional role of the architect as generalist, critic, organizer, leader, and framer. The architect knows a little about everything and uses his or her foundational knowledge to analyze givens, offer insights, invent possibilities, and assemble experts.

Like the artist, the architect must also find meaning and define a conceptual framework to govern each project. Architecture is not a cut and paste game of roof gables and crown moldings; it is an art form that constructs and narrates the human experience.

It is true that the architect lies under two perhaps conflicting umbrellas-artist and professional. This conflict has often been placated with terms such as "practical arts" or "design", but the point remains that architects often do act as artists. Rather than define strict roles of artist and architect on a design team, it may therefore be more productive to explore the artist and architect's shared skills and how they can leverage them to make thoughtful and engaged places together.

\section{SOCIAL ETHICS}

As we examine the role of the artist, certain dangers emerge around the potentially self-serving and egotistical nature of the individual artist who answers to no one. Such an artist, within the premise that the next frontier for art is social and environmental engagement, risks exploiting underprivileged, disabled, minority, or other disadvantaged populations for art-making. First, new focusses on addressing, solving, or bringing attention to the problems of certain groups necessarily make these groups the subjects of this art and thus the pawns of the art game. (What stops artists from using these populations in the production of their art and then moving on in a value system that has transformed from studio artist gallery shows to avant-garde demonstrations of political correctness?) Second, the emphasis on social and environmental concerns transforms art into something that is indeed practical, bleeding into the territories of applied arts and design fields. (Haven't design and architecture long offered a nexus of art and function? Can artists truly claim this ground as their own?)

The discussion of shifting values within the cultural sphere has already emerged within architectural discourse, with the recent regaling of star architects who dedicate their efforts toward social and environmental goals. Two of the most recent laureates of architecture's premier trophy, the Pritzker Prize, are architects engaged in this type of work: Alejandro Aravena, known for his social housing projects, and Shigeru Ban, known for his innovative use of paper tubes and environmental sensitivity. While such practices do add great value to architectural discourse and the larger cultural narrative, the flashy headlines of social engagement and environmentalism obscure discussions of the many other facets and feats of architectural practice. It follows that a value system so heavily favoring such singular aspects necessarily denies nuanced work the discussion that it merits. The result this emphasis has on the larger built environment is one shutting out ideas that don't reflect on-trend ethics. While social and environmental ambitions are noble, other ambitions cannot be overlooked as they contribute in their own right to the success of the built environment.

\section{SOCIALLY ENGAGING PLACE}

The tenets of socially engaged practice demand a sensitivity to place, or else risk a phenomenon observed by art critic Jeff Kelley:

What too many artists did was to parachute into a place and displace it with art [...] Site specificity was really more like the imposition of a kind of disembodied museum zone onto what had already been very meaningful and present before that, which was the place..$^{11}$

While working in the public domain, some artists drag the walls of the gallery with them, making objects more suited to a vacuum of white space than the immediate surrounds. Place must then become more central to the conceptualization, content, and performance of art in the public sphere, just as with the siting of architecture.

For art, the idea of place poses certain challenges. If artists normally bring a particular interest, bias, or problem with them into their art, then the given condition of place is a disruptor of the artist's narrative, bringing a newfound tension into play. For artists used to defining the topic to be addressed by their art, the idea of place at least in part intervenes. On the other hand, architects necessarily grapple with place on every new project, analyzing site conditions, traffic flows, demographics, use patterns, histories, and ambitions. Place is (or should be) an actor in any architectural project, though many architects think about place in a purely physical sense. Combining social strategies from art and contextual approaches from architecture may strengthen both practices.

Architects interested in progressing public interest design and practicing as a Citizen Architect may look to examples of socially engaged art that join social narratives with specific spatial settings. The success of such practices rests on the initial step of forming relationships with communities and seeing locals as partners in the production of both art and place. For example, Theaster Gates' art is that of placemaking; he creates destinations in blighted areas that are themselves educational devices that mix culture and art. Recognizing the power of community, he assembles teams of artists, architects, developers, community activists, and educators to obtain land, renovate buildings, and program them with events that engage both locals and outsiders. While both the positive critical reception and the public success of his projects are a testament to the power of such 

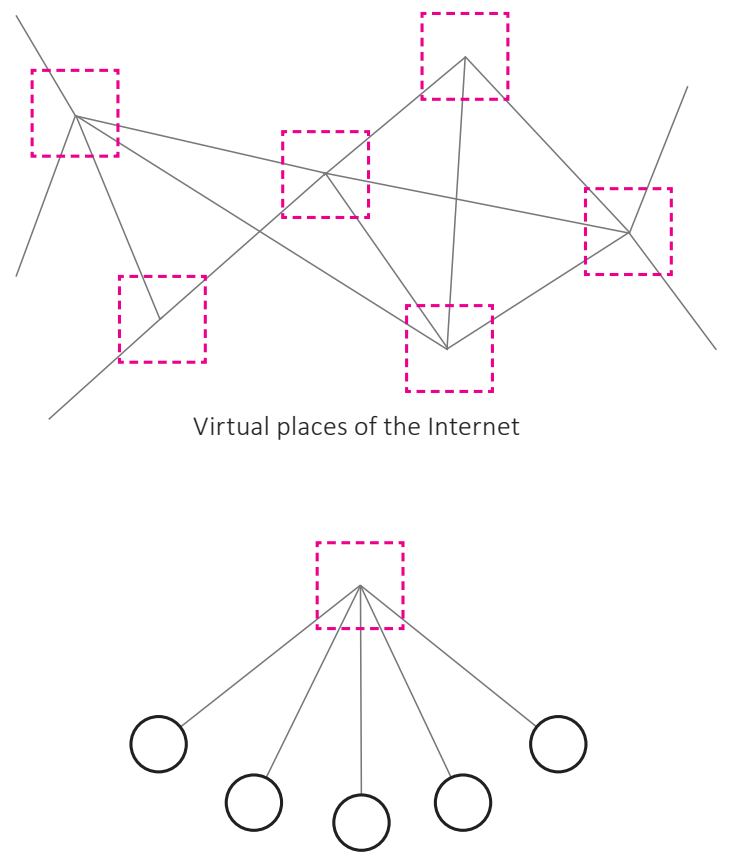

Miranda July crowdsources artists to create a virtual place

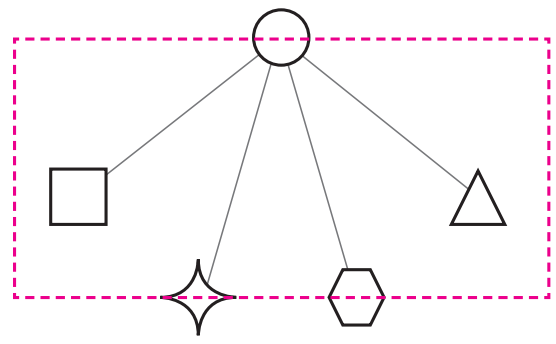

Theaster Gates brings locals and outsiders together to collaboratively create a physical

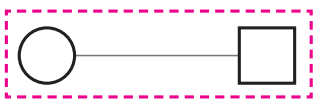

Dan Borelli works within an existing place (his hometown) to reconcile fond memories with the unfortunate legacy of local industry

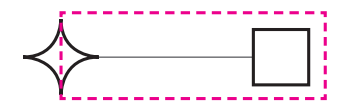

Assemble works with and becomes a long term part of local community to create places in derelict spaces
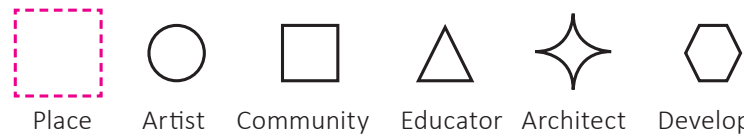

Place Artist Community Educator Architect Developer multidisciplinary efforts, the triumph of his projects and their impact on surrounding communities is two-sided. While the projects strengthen local communities, they also draw outsiders to the location, which may result in raised rents and gentrified communities. This downside is another example of how economics often undermine art practices, particularly social practice. Nonetheless, Helguera's definition of engaging community supports the type of work done by Gates-work that is targeted, participatory, and contextual. ${ }^{12}$ Gates mediates two communities (the social and the physical) in an attempt to find common ground.

Artist Dan Borelli's work addresses his experience growing up in Ashland, Massachusetts, where industrial chemical pollution from the Nyanza dye plant led to Superfund site classification. Known as the "chemical brook" for its changing hues, the site leached pollutants into the daily lives of Ashland inhabitants, bringing beautiful color (rainbow icicles and the like) but also a rare form of cancer to many residents. Borelli's work deals with the specifics of site - the social, cultural, ecological, and political makeup of a particular place - in order to engage his community and its history through art making. After authoring a visual and oral history of the town, Borelli called for other local communities to be their own advocates in telling their histories and sharing their cultures.

London based architecture collective Assemble bridges the gap from socially engaged practice to architecture. Eighteen members work together to identify funding sources, socially activate sites, create materials alongside community members, and collaboratively construct interventions for gathering. These efforts have resulted in a variety of built works, including The Cineroleum, a screening space at a decommissioned gas station, Folly for a Flyover, a performance space nestled under a motorway, Sugarhouse Studios, an affordable work-space complex in a former industrial building, and The Granby Workshop, a meeting ground for Liverpool's local Community Land Trust. Each project is equal parts social connector, thoughtfully designed space, and community-built point of pride, establishing both new places but also new frameworks for interaction in these communities. The 2015 awarding of the Turner Prize, one of the United Kingdom's highest art honors, to Assemble is a testament to the group's success at eschewing disciplinary bounds.

\section{TEACHING PLACE}

While art practice has historically drawn from regional techniques, a contemporary emphasis on gallery products, celebrity art practices, and cultivating a brand often overshadows a connection with place.

Educator and art theorist Mark A. Graham advocates for addressing the inherent absence of place in art education: 
Place based education is a response to standardized pedagogy that neglects local human and ecological communities. It draws on progressive traditions of multidisciplinary, authentic learning that seek to extend learning beyond the walls of the school. ${ }^{13}$

Graham's approach enables students to explore ideas of nature, community, culture, and ecology as a first step in nurturing place. Showing students the fluidity between what they learn and where it can be applied prepares them to implement their training meaningfully in their own communities.

Beyond disciplinary discussions, the larger world is shaped by the forces of globalization in the form of big box stores, mass media, and economies of scale. Given the matte condition of American commercial corridors, nuances of culture and histories of place begin to fade. The potential to preserve, nurture, and grow place within the American context will take active intervention and collaboration across disciplines.

Just as architects have borrowed from the formal preoccupations and conceptual streams of art practice, they will benefit from once more going to the well in order to integrate ethics into architectural education, theory, and practice. Building on the approaches of social media and network art, socially engaged art practice offers a lean and effective method for developing and making visible social networks within physical communities and breathing life back into impoverished and obsolete spaces. Rather than physical intervention, such art focusses on cultivating public discourse to create meaning, culture, and place. The success of multidisciplinary efforts in this vein suggest that architecture too can align with social practice, building social infrastructures which in turn strengthen physical environments and communities.

\section{ENDNOTES}

1 The American Institute of Architects defines a Citizen Architect as one who "uses his/her insights, talents, training, and experience to contribute meaningfully, beyond self, to the improvement of the community and human condition. The Citizen Architect stays informed on local, state, and federal issues, and makes time for service to the community. The Citizen Architect advocates for higher living standards, the creation of a sustainable environment, quality of life, and the greater good. The Citizen Architect seeks to advocate for the broader purposes of architecture through civic activism, writing and publishing, by gaining appointment to boards and commissions, and through elective office at all levels of government." "Citizen Architect," AIA Knowledge Net, (2018), https://network.aia.org/centerforcivicleadership/ home/citizenarchitect.

2 Richard C. Stedman, "Is It Really Just a Social Construction?: The Contribution of the Physical Environment to Sense of Place," Society \& Natural Resources 16, no. 8 (2003): 675

3 Sean Cubitt, "From Internationalism to Transnations: Networked Art and Activism," in At a Distance: Precursors to Art and Activism on the Internet, eds. Annmarie Chandler and Norie Neumark (Cambridge, MA: MIT Press, 2005), 433.

4 Pablo Helguera, Education for Socially Engaged Art: A Materials and Techniques Handbook, (Bethesda, MD: Jorge Pinto Books Inc., 2011), 3.

5 Claire Pentecost, "Critical Strategies in Art and Media - Introductory statement 04 - Claire Pentecost," Future Non Stop: A Living Archive for Digital Culture in Theory and Practice, (2010), http://future-nonstop.org/c/ ca69656fff0a0fb28ee6f3ab64c2e6c8.

6 Henry A. Giroux, "Public Pedagogy and the Politics of Neo-Liberalism: Making the Political More Pedagogical," Policy Futures in Education 2, no. 3 \& 4 (2004): 499.
7 Martin Zebracki, "Does Cultural Policy Matter in Public-Art Production? The Netherlands and Flanders Compared, 1945-Present," Environment and Planning A: Economy and Space 43 (2011): 2969.

9

id., 4

10 Ibid., 54.

11 Suzanne Lacy, "Debated Territory: Toward a Critical Language for Public Art," in Mapping the Terrain: New Genre Public Art, ed. Suzanne Lacy (Seattle, WA: Bay Press, 1996), 24

12 Helguera, Education for Socially Engaged Art, 25.

13 Mark A. Graham, "Art, Ecology and Art Education: Locating Art Education in a Critical Place-based Pedagogy," Studies in Art Education 48, no. 4 (2007): 377. 